Check for updates

Cite this: Chem. Commun., 2019, 55, 10725

Received 15th May 2019,

Accepted 3rd July 2019

DOI: $10.1039 /$ c9cc03749g

rsc.li/chemcomm

\section{Aerosol-based synthesis of pure and stable amorphous calcium carbonate $\dagger$}

\author{
Jacinta M. Xto, (D)*ab Camelia N. Borca, (D) Jeroen A. van Bokhoven (D) ab and \\ Thomas Huthwelker (D)*a
}

\begin{abstract}
A facile aerosol-based method for the synthesis of pure and stable amorphous calcium carbonate (ACC) is presented. The method relies on the instantaneous carbonation of calcium hydroxide aerosols with carbon dioxide followed by rapid drying of the freshly formed ACC. The ACC display extended stability against humidity induced crystallization.
\end{abstract}

The polymorphism of calcium carbonate is extensively studied in chemistry, mineralogy and earth science and most recently more intensively for carbon dioxide capture and storage technologies. ${ }^{1,2}$ Calcite, aragonite and vaterite are anhydrous polymorphs of $\mathrm{CaCO}_{3}$ and ikaite and monohydrocalcite are hydrated polymorphs. ${ }^{3,4}$ During precipitation reactions of calcium carbonate from supersaturated solutions, formation of transient amorphous calcium carbonate (ACC) has been reported in a variety of synthetic systems. ${ }^{5-13}$ In calcifying organisms, transient ACC formation has also been extensively reported ${ }^{10,14}$ and it has been postulated that the structure of the ACC largely determines which crystalline phase is formed. ${ }^{15,16}$ The remarkable architectures displayed in the brittle star lens, nacre and the sea urchin spicules, for example, have been associated to the remarkable control over ACC crystallization. ${ }^{10,17-19}$

With increasing evidence pointing to the role of ACC in formation of biologically relevant functional materials, there has been an increase of interest in ACC formation and crystallization for their potential application in industry and materials synthesis. ${ }^{20-24}$ A variety of ACC synthesis methods have been developed, most of which rely on additives such as magnesium/ sulphate ions or organic additives/solvents. ${ }^{6,25-27}$ The presence of these additives affects the nature and crystallization behaviour of ACC in different ways. The synthesis protocol, presence of co-precipitated ions, amount of mobile water, temperature, $\mathrm{pH}$

\footnotetext{
${ }^{a}$ Paul Scherrer Institut, 5232 Villigen, Switzerland.

E-mail: Thomas.huthwelker@psi.ch

${ }^{b}$ Institute for Chemical and Bioengineering, ETH Zürich, 8093 Zürich, Switzerland $\dagger$ Electronic supplementary information (ESI) available: Experimental details, additional SEM images and particle size distribution. See DOI: 10.1039/c9cc03749g
}

and drying conditions are among the factors that have been suggested to affect ACC crystallization. ${ }^{16,28-33}$ However, without a pure ACC reference, it is not possible to correlate these factors. Therefore, to fully understand and exploit the potential of ACC, there is a need to develop facile and reproducible synthesis methods of additive-free and stable ACC reference.

In this work, we present a facile and reproducible aerosolbased method for the formation of pure and stable ACC. The method relies on the rapid reaction of calcium hydroxide aerosols with carbon dioxide (eqn (1)). The subsequent rapid drying of the ACC aerosols using a diffusion drier prevents crystallization and results in the formation of pure, stable and dry ACC.

$$
\mathrm{Ca}(\mathrm{OH})_{2}(\mathrm{aq})+\mathrm{CO}_{2}(\mathrm{~g}) \rightarrow \mathrm{CaCO}_{3}(\mathrm{~s})+\mathrm{H}_{2} \mathrm{O}(\mathrm{l})
$$

Fig. 1 shows a schematic of the aerosol-based system, consisting of a commercial available atomizer model 3076 from TSI$^{34}{ }^{34}$ a diffusion drier and a syringe pump (SPL with touch screen). A high velocity gas jet forms from the expansion of 2.5 bars carbon dioxide through a $0.0135 \mathrm{~mm}$ orifice into the atomizer. The carbon dioxide jet atomizes a fresh calcium hydroxide solution, which is continuously fed with a syringe pump at a rate of $1 \mathrm{ml} \mathrm{min}^{-1}$ into a vertical passage.

Calcium hydroxide, being very basic $(\mathrm{pH} \sim 12)$, rapidly reacts with the carbon dioxide to form ACC aerosols. A fine spray consisting of droplets of about $300 \mathrm{~nm}^{34}$ in size follows the gas flow into a gas permeable tube in the diffusion dryer. Through impaction to the wall on the opposite side of the aerosol source, the larger droplets are collected into the drain solution at the bottom of the atomizer. From the atomizer, the ACC aerosol mist passes through a diffusion-drying chamber at a flow rate of $1.1 \mathrm{I} \mathrm{min}^{-1}$ where the water vapour is rapidly absorbed $(\sim 2$ minutes residence). The drier, which is filled with a desiccant (silica gel), is $50 \mathrm{~cm}$ in length and $7.5 \mathrm{~cm}$ in diameter, consisting of an inner water vapour permeable tube ( $\sim 6 \mathrm{~mm}$ diameter $)$ in which the aerosols pass through without direct contact with the desiccant. In addition, any particles, which hit the walls of the tubing, are lost 


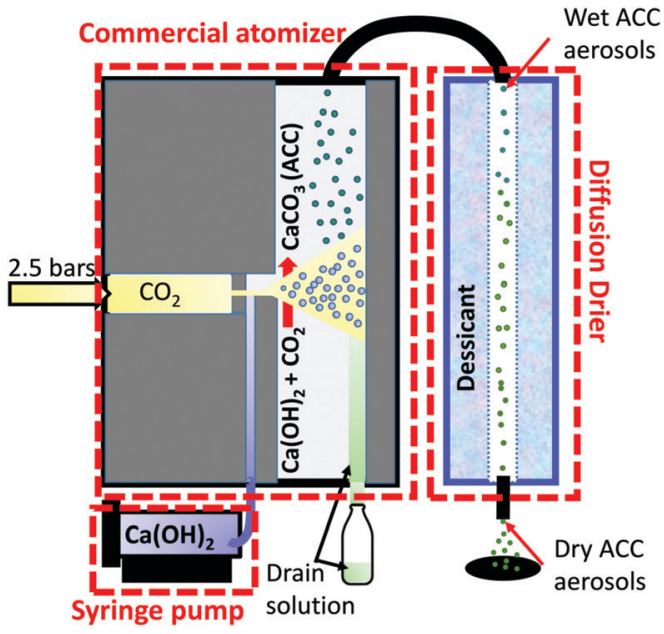

Fig. 1 Schematic of the aerosol synthesis of dry amorphous calcium carbonate (ACC).

from the gas flow hence the deposited ACC remain clean. EDX elemental analysis (Fig. S1, ESI $\dagger$ ) on the deposited ACC and the absence of absorption bands characteristic of organic compound in the IR spectra confirmed the purity of the ACC.

The size distribution of the dry ACC is controlled by the initial concentration of the calcium hydroxide solution used. By using a condensation particle counter (CPC) the particle size distribution can be established and calibrated with respect to the calcium hydroxide solution. The particle size distribution Fig. 2 and the plot in (Fig. S2, ESI $\dagger$ ) of the mean particle diameter as a function of concentration shows that using a $20 \mathrm{mM}$ calcium hydroxide solution results in bigger ACC (mean size: $\sim 100 \mathrm{~nm}$ ) whereas a $1 \mathrm{mM}$ calcium hydroxide results in smaller ACC particles (mean size $\sim 60 \mathrm{~nm}$ ). In addition, scanning electron microscopy (SEM) images in Fig. 3 (also Fig. S3, ESI $\dagger$ ) shows that ACC generated from low calcium hydroxide concentration are well dispersed on the surface and do not agglomerate possibly due to their much smaller size. However, for higher concentrations, the ACC particles are much bigger in size thereby tend to quickly agglomerate. Control over ACC size distribution and

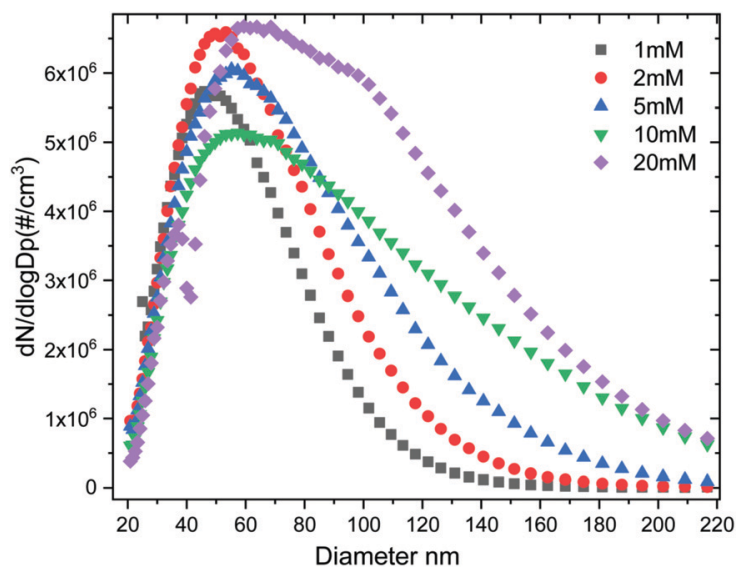

Fig. 2 Number size distribution of aerosol ACC generated from different concentrations of calcium hydroxide.
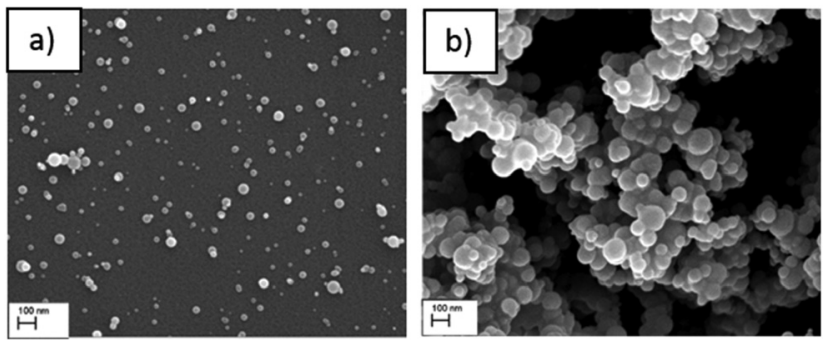

Fig. 3 SEM images of aerosol ACC prepared from (a) a $2 \mathrm{mM} \mathrm{Ca}(\mathrm{OH})_{2}$ solution and (b) a $20 \mathrm{mM} \mathrm{Ca}(\mathrm{OH})_{2}$ solution (scale bar $100 \mathrm{~nm}$ ).

agglomeration is therefore tuneable simply by adjusting the calcium hydroxide solution concentration and sample collection time.

The Ca K-edge XANES features of the aerosol-ACC in Fig. 4 are consistent with literature, ${ }^{14,31}$ displaying a pre-peak at $\sim 4039 \mathrm{eV}$ similar to that in vaterite indicating the ACC structure is non centrosymmetric. The single broad white line at $4049 \mathrm{eV}$ distinguishes the spectrum of the ACC from that of vaterite, which has a shoulder peak at $\sim 4044.5 \mathrm{eV}$, a white line peak at $\sim 4047.9 \mathrm{eV}$ and a post edge feature centred at $\sim 4056 \mathrm{eV}$. The ACC XANES spectrum is also distinctively different from that of calcite, which displays a doubly split pre-edge feature at $\sim 4038.6 \mathrm{eV}$ and $\sim 4039.8 \mathrm{eV}$, a shoulder peak at $\sim 4044 \mathrm{eV}$, a white line peak at $\sim 4047.3 \mathrm{eV}$ and a further post edge feature centred at $4060 \mathrm{eV}$. The Ca K-edge XANES spectrum of calcium hydroxide on the other hand lacks a distinct pre-edge feature and is characterized by a shoulder peak at $\sim 4043.5 \mathrm{eV}$, a white line peak at $\sim 4050 \mathrm{eV}$ and a post edge features which is in stark contrast to the ACC spectrum confirming the successful carbonation of the $\mathrm{Ca}(\mathrm{OH})_{2}$. The IR spectrum in Fig. 5 of the aerosol ACC also compares well with documented IR spectra of ACC. . $^{14,15,35,36}$ It is characterized by a doubly split asymmetric carbonate ion stretch at 1482 and $1420 \mathrm{~cm}^{-1}\left(\nu_{3}\right)$ indicative of lack of symmetry around the carbonate ion, a peak at $1073 \mathrm{~cm}^{-1}\left(\nu_{1}\right)$, an out-of-plane bending vibration at $864 \mathrm{~cm}^{-1}\left(\nu_{2}\right)$ and a broad in-plane bending vibration centred at $690 \mathrm{~cm}^{-1}\left(\nu_{4}\right) \cdot{ }^{37}$ A broad $\mathrm{O}-\mathrm{H}$ broad stretching vibration

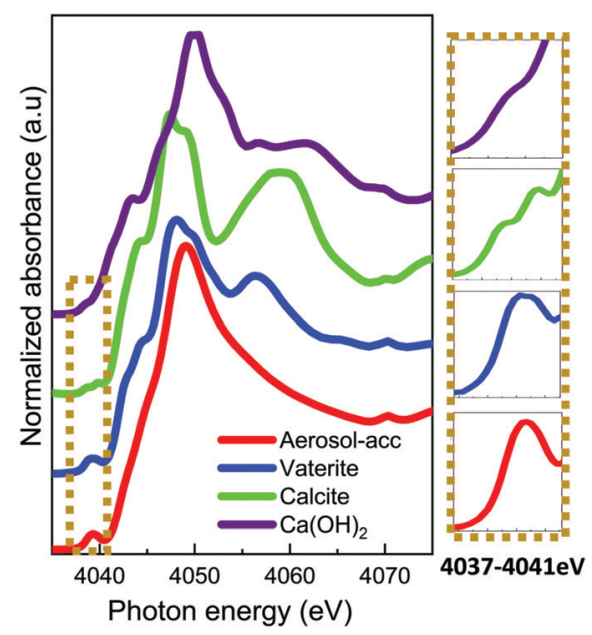

Fig. 4 Ca K-edge XANES spectra of aerosol ACC, vaterite, calcite and calcium hydroxide. 


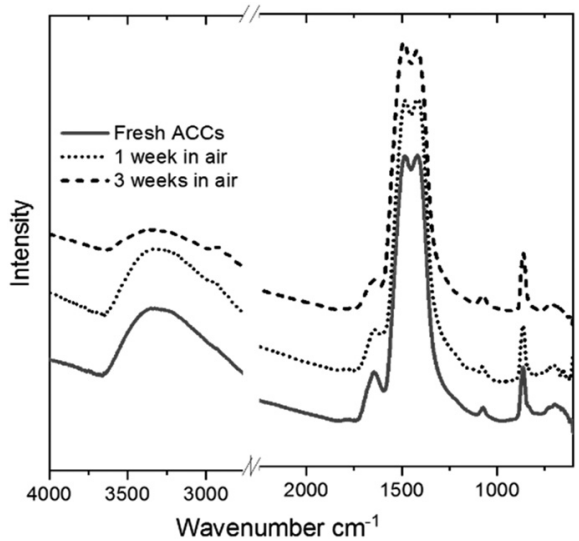

Fig. 5 IR spectrum of freshly prepared dry aerosol ACC and exposed to air for 1 and 3 weeks.

between 2700 and $3600 \mathrm{~cm}^{-1}$ and $\mathrm{H}-\mathrm{O}-\mathrm{H}$ bending vibration at $1650 \mathrm{~cm}^{-1}$ indicative of bound structural water, which is characteristic of ACC.

The significant absence of a sharp peak at $3640 \mathrm{~cm}^{-1}$ is a further confirmation of the complete carbonation of calcium hydroxide. ${ }^{38}$ When left exposed to air ( $\sim 33 \%$ relative humidity), the aerosol ACC show remarkable stability against crystallization with no observable difference noted in the IR spectra of the ACC even after 3 weeks in air. Upon exposure to very high relative humidity, a variety of ACC have been reported to rapidly crystallize to vaterite or calcite. ${ }^{35,39,40}$ However, at a relative humidity of up to $\sim 90 \%$, the aerosol ACC display remarkable stability for extended periods. Fig. 6a shows time-resolved in situ Ca K-edge XANES measurements collected for 22 hours with continuous exposure of the aerosol ACC to $85 \%$ relative humidity. No evident changes in the spectra of the ACC are noted indicating their enhanced stability. However, despite the fact that there are no evident peaks characteristic of vaterite at $745 \mathrm{~cm}^{-1}$ or calcite at $713 \mathrm{~cm}^{-1}$ after 8 days of continuous $\sim 90 \%$ relative humidity exposure, some structural changes are observed in the IR spectra
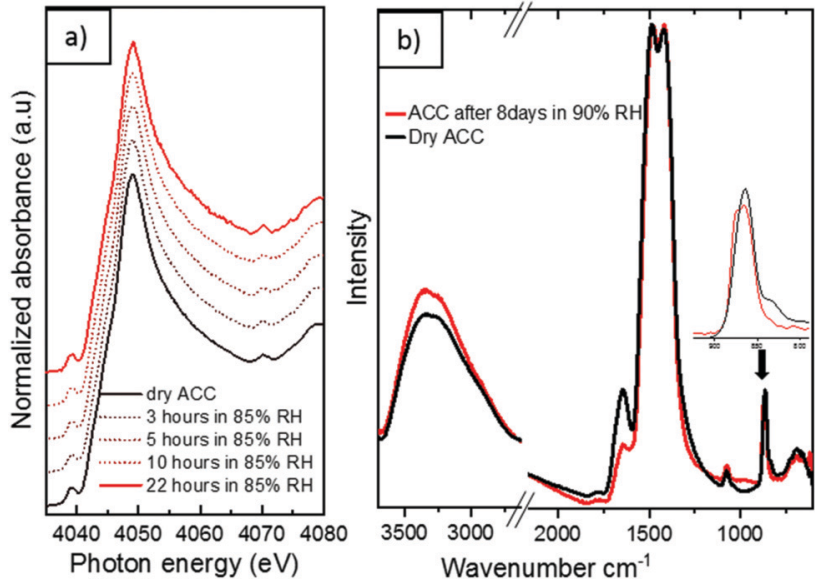

Fig. 6 (a) In situ Ca K edge XANES of aerosol ACC during humidification with $85 \% \mathrm{RH}$ for 22 hours (b) IR spectra of aerosol ACC before and after 8 days of $90 \%$ relative humidity $(\mathrm{RH})$ exposure. in Fig. 6b (also XANES in Fig. S4 ESI $\dagger$ ). There is a broadening of the peak at $864 \mathrm{~cm}^{-1}$ with a small shift to higher wavenumbers and the broad $\mathrm{O}-\mathrm{H}$ stretching vibration between 2700 and $3600 \mathrm{~cm}^{-1}$ increases in intensity whereas the $\mathrm{H}-\mathrm{O}-\mathrm{H}$ bending vibration at $1650 \mathrm{~cm}^{-1}$ decreases in intensity. This suggests that water induced structural changes occur in the aerosol ACC after several days of very high humidity exposure.

We hypothesize that the enhanced stability of the aerosol ACC could be due to their purity and low water content arising from the rapid airborne drying. Most ACC synthesis procedures usually involve mixing two aqueous solutions, thereby traces of both salts from the counter ions, ${ }^{32}$ and water are inevitable. This hypothesis is consistent with observations from counter ion free freeze-dried ACC synthesized by Ihli et al. ${ }^{27}$ which also exhibit enhanced stability for up to six weeks when left exposed to air. In addition, it has been proposed that the presence of mobile water in the ACC accelerates its crystallization, ${ }^{31,32,40,41}$ herein we rapidly dry individual airborne ACC before deposition on the sample holder thereby decreasing the probability of having trapped mobile water within the ACC aggregates upon deposition.

The aerosol-based synthesis of ACC presents a facile and reproducible approach of synthesizing impurity-free stable ACC.

These pure ACC can be used as references during studies on the structure and transformation of ACC prepared in the presence of counter ions $\left(\mathrm{Na}^{+} / \mathrm{Cl}^{-}\right)$, impurities such as $\mathrm{Mg}^{2+}$ and $\mathrm{PO}_{4}{ }^{2-}$ ions or using other solvents such as ethanol and isopropanol. Having a consistent and reproducible reference will ultimately benefit the ongoing research on factors that control the crystallization pathway of ACC. In addition, other fields, such as bio-inspired material synthesis/drug delivery that rely on the purity and stability ACC may profit from this synthesis approach.

We thank the SNF (200021_157148) for financial support, the PHOENIX beamline at the Swiss Light source (Villigen, PSI) for beam time and Prof. Dr M. Ammann and Dr Peter Aaron Alpert for provision of a CPC and for helpful discussions.

\section{Conflicts of interest}

There are no conflicts to declare.

\section{Notes and references}

1 M. Kim, S. Choi, S. Kim, S. Lee, Y. Park and R. Chang, Calcium Carbonate Precipitation for $\mathrm{CO}_{2}$ Storage and Utilization: A Review of the Carbonate Crystallization and Polymorphism, Front. Energy Res., 2017, 5, 1-12.

2 Intergov. Panel Clim. Chang., ed. B. Metz, O. Davidson, H. de Coninck, M. Loos and L. Meyer, 2009, pp. 1-31.

3 W. Sekkal and A. Zaoui, Nanoscale analysis of the morphology and surface stability of calcium carbonate polymorphs, Sci. Rep., 2013, 3, 1587.

4 G. S. Dieckmann, G. Nehrke and C. Uhlig, Brief Communication: Ikaite $\left(\mathrm{CaCO}_{3} \cdot 6 \mathrm{H}_{2} \mathrm{O}\right)$ discovered in Arctic sea ice, Cryosph., 2010, 227-230.

5 J. De Yoreo, More than one pathway, Nat. Publ. Gr., 2013, 12, 284-285.

6 R. Carlos, K. Kudłacz, Ö. Cizer and R. Encarnacion, Formation of amorphous calcium carbonate and its transformation into mesostructured calcite, CrystEngComm, 2015, 17, 58-72.

7 M. Faatz, F. Gröhn and G. Wegner, Amorphous calcium carbonate: Synthesis and potential intermediate in biomineralization, Adv. Mater., 2004, 16, 996-1000. 
8 C. Rodriguez-Navarro, A. Burgos Cara, K. Elert, C. V. Putnis and E. Ruiz-Agudo, Direct Nanoscale Imaging Reveals the Growth of Calcite Crystals via Amorphous Nanoparticles, Cryst. Growth Des., 2016, 16, 1850-1860.

9 J. D. Rodriguez-Blanco, S. Shaw and L. G. Benning, The kinetics and mechanisms of amorphous calcium carbonate (ACC) crystallization to calcite, via vaterite, Nanoscale, 2011, 3, 265-271.

10 R. T. Devol, C. Sun, M. A. Marcus, S. N. Coppersmith, S. C. B. Myneni and P. U. P. A. Gilbert, Nanoscale Transforming Mineral Phases in Fresh Nacre, J. Am. Chem. Soc., 2015, 137, 13325-13333.

11 D. Pontoni, J. Bolze, N. Dingenouts, T. Narayanan, M. Ballauff and V. Uni, Crystallization of Calcium Carbonate Observed In situ by Combined Small- and Wide-angle X-ray Scattering, J. Phys. Chem., 2003, 5123-5125.

12 A. Navrotsky, Energetic clues to pathways to biomineralization: Precursors, clusters, and nanoparticles, Proc. Natl. Acad. Sci. U. S. A., 2004, 101, 12096-12101.

13 E. M. Pouget, P. H. H. Bomans, J. A. C. M. Goos, P. M. Frederik, I. W. De and N. A. J. Sommerdijk, $\mathrm{CaCO}_{3}$ Formation Revealed by Cryo-TEM, Science, 2009, 323, 1455-1458.

14 B. Y. Politi, Y. Levi-kalisman, S. Raz, F. Wilt, L. Addadi, S. Weiner and I. Sagi, Structural Characterization of the Transient Amorphous Calcium Carbonate Precursor Phase in Sea Urchin Embryos, Adv. Funct. Mater., 2006, 16, 1289-1298.

15 D. Gebauer, P. N. Gunawidjaja, J. Y. P. Ko, Z. Bacsik, B. Aziz, L. Liu, Y. Hu, L. Bergström, C. W. Tai, T. K. Sham, M. Edén and N. Hedin, Proto-calcite and proto-vaterite in amorphous calcium carbonates, Angew. Chem., Int. Ed., 2010, 49, 8889-8891.

16 M. Farhadi-khouzani, D. M. Chevrier, P. Zhang, N. Hedin and D. Gebauer, Amorphous Calcium Carbonate Water as the Key to Proto-Aragonite, Angew. Chem., Int. Ed., 2016, 8117-8120.

17 Y. Ma, B. Aichmayer, O. Paris, P. Fratzl, A. Meibom, R. A. Metzler, Y. Politi, L. Addadi, P. U. P. A. Gilbert and S. Weiner, The grinding tip of the sea urchin tooth exhibits exquisite control over calcite crystal orientation and $\mathrm{Mg}$ distribution, Proc. Natl. Acad. Sci. U. S. A., 2009, 106, 6048-6053.

18 M. Eder, S. Amini and P. Fratzl, Biological composites-complex structures for functional diversity, Science, 2018, 362, 543-547.

19 D. M. Duffy, Coherent nanoparticles in calcite, Science, 2017, 358, 1254-1255.

20 J. T. Avaro, C. Ruiz-Agudo, E. Landwehr, K. Hauser and D. Gebauer, Impurity-free amorphous calcium carbonate, a preferential material for pharmaceutical and medical applications, Eur. J. Mineral., 2019, 31, 231-236.

21 S. Matsumura, T. Sakamoto, T. Nishimura, B. Cantaert, T. Kato and D. Kuo, Use of Amorphous Calcium Carbonate for the Design of New Materials, ChemPlusChem, 2016, 82, 107-120.

22 U. G. K. Wegst, H. Bai, E. Saiz, A. P. Tomsia and R. O. Ritchie, Bioinspired structural materials, Nat. Mater., 2015, 14, 23-36.

23 J. W. Smith and R. J. Saykally, Soft X-ray Absorption Spectroscopy of Liquids and Solutions, Chem. Rev., 2017, 117, 13909-13934.

24 S. Weiner and L. Addadi, Crystallization Pathways in Biomineralization, Annu. Rev. Mater. Res., 2011, 41, 21-40.
25 S. Chen, H. Colfen, M. Antonietti and S. Yu, Ethanol assisted synthesis of pure and stable amorphous calcium carbonate nanoparticles, Chem. Commun., 2013, 49, 9564-9566.

26 N. Koga, Y. Nakagoe and H. Tanaka, Crystallization of amorphous calcium carbonate, Thermochim. Acta, 1998, 318, 239-244.

27 J. Ihli, A. N. Kulak and F. C. Meldrum, Freeze-drying yields stable and pure amorphous calcium carbonate (ACC), Chem. Commun., 2013, 49, 3134-3136.

28 Y. Politi, D. R. Bachelor, P. Zaslansky, B. F. Chmelka, J. C. Weaver, I. Sagi, S. Weiner and L. Addadi, Role of Magnesium Ion in the Stabilization of Biogenic Amorphous Calcium Carbonate: A Structure Function Investigation, Chem. Mater., 2009, 22, 161-166.

29 E. Loste, R. M. Wilson, R. Seshadri and F. C. Meldrum, The role of magnesium in stabilising amorphous calcium carbonate and controlling calcite morphologies, J. Cryst. Growth, 2003, 254, 206-218.

30 T. Roncal-Herrero, P. Bots, S. Shaw, J. D. Rodriguez-Blanco and L. G. Benning, The role of $\mathrm{pH}$ and $\mathrm{Mg}$ on the stability and crystallization of amorphous calcium carbonate, J. Alloys Compd., 2011, 536, S477-S479.

31 H. Du, M. Steinacher, C. Borca, T. Huthwelker, A. Murello, F. Stellacci and E. Amstad, Amorphous $\mathrm{CaCO}_{3}$ : Influence of the Formation Time on Its Degree of Hydration and Stability, J. Am. Chem. Soc., 2018, 140, 14289-14299.

32 M. Albéric, L. Bertinetti, Z. Zou, P. Fratzl, W. Habraken and Y. Politi, The Crystallization of Amorphous Calcium Carbonate is Kinetically Governed by Ion Impurities and Water, Adv. Sci., 2018, 5, 1701000.

33 Z. Zou, L. Bertinetti, Y. Politi, A. C. S. Jensen, S. Weiner, L. Addadi, P. Fratzl and W. J. E. M. Habraken, Opposite Particle Size Effect on Amorphous Calcium Carbonate Crystallization in Water and during Heating in Air, Chem. Mater., 2015, 27, 4237-4246.

34 B. Y. H. Liu and K. W. Lee, An aerosol generator of high stability, Am. Ind. Hyg. Assoc. J., 1975, 36, 861-865.

35 S. F. Chen, H. Cölfen, M. Antonietti and S. H. Yu, Ethanol assisted synthesis of pure and stable amorphous calcium carbonate nanoparticles, Chem. Commun., 2013, 49, 9564-9566.

36 R. S. K. Lam, J. M. Charnock, A. Lennie, C. Fiona, R. S. K. Lam, J. M. Charnock and F. C. Meldrum, Synthesis-dependant structural variations in amorphous calcium carbonate, CrystEngComm, 2007, 9, 1226-1236.

37 L. Addadi, S. Raz and S. Weiner, Taking advantage of disorder: Amorphous calcium carbonate and its roles in biomineralization, Adv. Mater., 2003, 15, 959-970.

38 M. Khachani, A. El Hamidi, M. Halim and S. Arsalane, Nonisothermal kinetic and thermodynamic studies of the dehydroxylation process of synthetic calcium hydroxide $\mathrm{Ca}(\mathrm{OH})_{2}, J$. Mater. Environ. Sci., 2014, 5, 615-624.

39 X. Xu, J. T. Han, D. H. Kim and K. Cho, Two modes of transformation of amorphous calcium carbonate films in air, J. Phys. Chem. B, 2006, 110, 2764-2770.

40 F. Konrad, F. Gallien, D. E. Gerard and M. Dietzel, Transformation of Amorphous Calcium Carbonate in Air, Cryst. Growth Des., 2016, 16, 6310-6317.

$41 \mathrm{H}$. Du and E. Amstad, Water: How does it influence the $\mathrm{CaCO}_{3}$ formation?, Angew. Chem., 2019, DOI: 10.1002/ange.201903662. 